\title{
A METODOLOGIA ASSISTENCIAL DE ENFERMAGEM NA PRÁTICA - HOSPITAL UNIVERSITARIO DA USP
}

\author{
Maria Coeli Campedelli* \\ Raquel Rapone Gaidzinski**
}

CAMPEDELLI, M.C.: GAIDZINSKZI, R.R. A metodologia assistencial de enfermagem na prática - Hospital Universitário da USP. Rev. Esc. Enf. USP, São Paulo, 21(no/especial): $62-67,1987$.

\section{INTRODUÇAO}

E com grande orgulho que nós Enfermeiras do Departamento de Assistência de Enfermagem do Hospital Universitário (H. U.) da USP estamos aqui neste evento, na Semana Wanda de Aguiar Horta, para fazer parte desta sessão cujo tema é "A Metodologia Assistencial de Enfermagem na Prática".

Estamos muito a vontade para apresentar este trabalho, uma vez que esta metodologia foi muito bem implantada em 1981, quando era Diretora da Divisão de Enfermagem a Prof ${ }^{\mathfrak{a}} \mathrm{Dr}^{\mathfrak{a}}$ Tamara Iwanow Cian. ciarullo.

A metodologia, já naquela época, recebeu o nome de Sistemática de Assistência de Enfermagem (S. A. E.) utilizando três fases do Processo de Enfermagem: Histórico, Evolução e Prescrição.

A atual direção do Departamento de Assistência de Enfermagem deseja ressaltar que caso esta metodologia não tivesse sido implantada com todos os requisitos adequados, não poderiamos hoje apresentar a S. A. E. no estágio em que se encontra.

Não tivemos que conquistar espaços, como por exemplo a introdução no prontuário, de um impresso específico para esta metodologia, pois isto também é mérito da equipe que fez a implantação. Nossa dificuldade é na manutenção desta metodologia na prática diária, pois existe uma rotatividade muito grande de enfermeira e de pessoal de enfermagem. Segundo dados da Sub-Divisão de Educação Continuada do H. U., esta rotatividade é grande principalmente em decorrência da procura de melhores condições de trabalho quanto a horário, salário e proximidade de residência. Na equipe de enfermagem o grupo que apresenta menor rotatividade proporcionalmente é o de enfermeiras.

\footnotetext{
* Professora Assistente da Escola de Enfermagem da USP e Diretor do Departamento de Assistência de Enfermagem do Hospital Universitário da USP.

* Diretor de Serviço da Clínica Médica do Departamento de Assistência de Enfermagem do IIospital Universitárío da USP.
} 
Outra grande dificuldade é a necessidade de orientação constante das equipes médicas responsáveis pelas novas unidades implantadas neste periodo. Quando percebemos que um grupo já está cônscio de um dos nossos métodos de trabalho, que é a Prescrição de Enfermagem, iniciase um novo grupo de alunos (internos de medicina), que começa a prescrever aos pacientes as cuidados de enfermagem.

As enfermeiras também apresentam questionamentos quase que diários, no sentido de modificar a metodologia ou parte dela, deixando transparecer que certas normas não estavam atualizadas e conseqüentemente muitas delas eram inexequíveis.

No H.U. existem grupos de trabalho que foram criados no intuito de dar suporte à administração do Departamento de Assistência de Enfermagem, cada um deles dentro de sua especificidade, para que a enfermagem tivesse condições de gerenciar suas atividades de forma mais técnica e científica. Estes grupos são:

1. Grupo de Procedimentos - que tem como finalidade padronizar e implementar os procedimentos de enfermagem utilizados pela equipe.

2. Grupo de equipamentos - responsável pelos procedimentos que normatizam a montagem, manuseio, desinfecção, manutenção e guarda dos equipamentos em todas as unidades do H.U.

3. Grupo de Extensão à Comunidade - estrutura e sistematiza os critérios para consulta de enfermagem e visita domiciliar.

4. Grupo da Educação Continuada - auxilia na formulação, implantação e avaliação de programas que favoreçam o desenvolvimento do pessoal de enfermagem.

5. Grupo de Auditoria - analisa a qualidade da assistência de enfermagem, fornecendo subsidios para a intervenção nos pontos críticos a fim de melhorar esta assistência.

Assim sendo, em 1985, o Departamento de Assistência de Enfermagem criou um novo grupo de trabalho com o objetivo de reavaliar a S.A.E., implantada há 4 anos, e propor normas condizentes com a nova realidade do hospital, assim como estabelecer as condutas necessárias aos problemas mais comuns de enfermagem. Estávamos preocupadas com a repercussão desta metodologia no dia a dia das enfermeiras, pois havia a indagação de como prescrever com a grande falta de funcionários. Questionava-se ainda se esta metodologia, se extinta, diminuiria o volume e a qualidade do trabalho.

Este grupo de trabalho é constituído por:

- 2 Representantes do Departamento de Assistência de Enfermagem;

- 1 Enfermeira Chefe de Unidade;

- 1 Enfermeira da Educação Continuada;

- 2 Enfermeiras de outras unidades e 
- 2 Docentes da EEUSP (sendo que uma exerce a função de Supervisora de Ensino e Pesquisa no H.U.).

Nas reuniões deste grupo optou-se pela elaboração de um questionário com a finalidade de identificar as dificuldades enfrentadas pela enfermeira na utilização das normas existentes à prática diária.

\section{APRESENTAÇAO DOS RESULTADOS}

O questionário foi preenchido por apenas 26 enfermeiras, já que o pré-requisito era estar há pelo menos 1 ano na Instituição, pois acreditava-se que a vivência na aplicação desta metodologia iria enriquecer em contribuições o estudo. Este questionário contava de 14 perguntas que possibilitaram analisar a situação da S.A.E. relacionadas a:

\subsection{Histórico de enfermagem}

O tempo médio gasto na aplicação do Histórico de Enfermagem foi de $38 \mathrm{~min}$. com um desvio padrão em torno da média de $10 \mathrm{~min}$.

Já quanto a ordem de preferência na utilização do Histórico, obtivemos $100 \%$ para utilização na $1^{\text {a }}$ Evolução e Prescrição de Enfermagem. Outras preferèncias foram também referendadas como se vê no diagrama $\mathrm{I}$.

DI A G R A M A I

PREFERENCIA. RELATIVA QUANTO A UTTLIZAÇAO DO HISTORICO DE ENFERMAGEM:

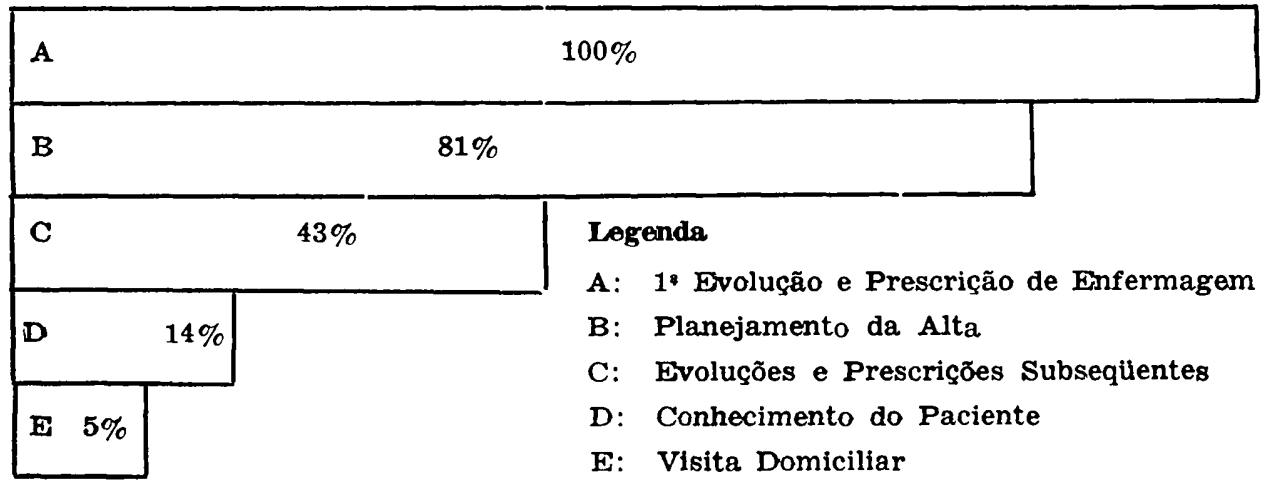

Com referência a utilização de todos os itens do Histónico, $77 \%$ das enfermeiras referiram que não utilizam todos os itens apresentados, conseqüentemente apenas $23 \%$ delas aproveitam todos os itens no planejamento da assistência. 


\subsection{Prescrição e evolução de enfermagem}

Para elaborar a Evolução e Prescrição de Enfermagem diánia as enfermeiras referiram valer-se das anotaçōes de enfermagem, evoluçōes e prescrições de enfermagem anteriores, prescrições e evoluçōes médicas, exames, resultados das discussões das visitas médicas e do histórico de enfermagem.

\section{QUADRO I}

DISTRIBUTÇAO DA QUANTIDADE E DO TEMPO MEDIO GASTO NAS UNIDADES ESTUDADAS, PARA EXECUÇAO DA EVOLUÇAO D PRESCRIÇAO DE ENFERMAGEM.

\begin{tabular}{l|c|c|c}
\hline \multicolumn{1}{c|}{ Unidades } & $\begin{array}{c}\text { Tempo Médio } \\
\text { Evoluço/Presc. }\end{array}$ & $\begin{array}{c}\text { Numero Médio } \\
\text { Evoluço/Presc. }\end{array}$ & $\begin{array}{c}\text { Tempo Médio } \\
\text { (horas) }\end{array}$ \\
\hline Clínica Médica & $30^{\prime}$ & 6 & $3: 00$ \\
\hline Pediatria & $20^{\prime}$ & 10 & $3: 20$ \\
\hline Pronto Atendimento & $20^{\prime}$ & 5 & $1: 40$ \\
\hline Centro Obstétrico & $10^{\prime}$ & 11 & $3: 29$ \\
\hline Berçário & $15^{\prime}$ & 9 & $2: 15$ \\
\hline Alojamento Conjunto & $16^{\prime}$ & 15 & $3: 45$ \\
\hline
\end{tabular}

Em relação ao tempo médio gasto nas fases da Evolução e Prescrição de Enfermagem, nota-se que a unidade que dispende maior tempo (30 min.) é a de Clínica Médica o que pode ser explicado frente a variedade de cuidados de enfermagem necessários ao atendimento dos pacientes nela internados. Por outro lado o menor tempo $(15 \mathrm{~min})$ e consequientemente o maior número (15) de evoluções e prescrições foi na unidade de Alojamento Conjunto tendo em vista que a clientela a ser atendida é considerada sadia. $\mathrm{Na}$ unidade de Pronto Atendimento vemos que é a unidade que apresenta o menor número (5) por plantão, pois dirige-se especificamente aos pacientes em observação, com o objetivo de atender aos problemas de enfermagem inerentes aos sinais e sintomas.

Quanto a Prescrição de Enfermagem obedecer a uma seqüência padronizada, $81 \%$ das enfermeiras a consideraram importante, referindo ser mais fácil para organizarem o seu raciocínio, enquanto que $19 \%$ referiram que é essencial que os cuidados estejam prescritos, independentemente da seqüência. 
Outro dado levantado diz respeito a necessidade diária da Evolução e Prescrição de Enfermagem a todos os pacientes. $68 \%$ das enfermeiras a consideraram imprescindivel a todos os pacientes, no entanto $32 \%$ justificaram que há exceções tais como: falta de funcionários (Evolução e Prescrição para os mais necessitados), pacientes de alta há mais de 24 hoias ou que já tenham assumido o seu auto-cuidado.

Comparando a dificuldade para a execução da Evolução e Frescrição encontramos a seguinte situação:

QUADRO II

PERCENTUAL POR DISTRIBUIÇAO DE DIFTCULDADES E FACILIDADES, QUANTO A EXXECUÇAO DA EVOLUÇAO E PRESCRIÇAO DE ENFERMAGEM.

\begin{tabular}{c|c|c}
\hline Elaboração & Evoluçao & Prescriçáo \\
\hline Com dificuldade & $40 \%$ & $62 \%$ \\
\hline Sem dificuldade & $60 \%$ & $38 \%$ \\
\hline
\end{tabular}

Nota-se que a maior dificuldade está na Prescrição de Enfermagem $(62 \%)$, o que é justificável na nossa realidade, tendo em vista que as condutas de enfermagem rém, $60 \%$ das enfernciras referiram não terem dificuldades para sintetizar os resultados dos cuidados prescritos frente aos problemas de enfermagem levantados, retratando a situação do paciente.

2.3. Atividades citadas para prestar assistência de enfermagem

Como atividades necessárias para tentar garantir uma boa assistência, os resultados, segundo a preferência relativa, mostraram-se conforme diagrama II.

DIAGR A M A I I

PREFERENCIA RELATTVA PARA GARANTIR UMA BOA ASSISTENCIA DE ENFERMAGEM.

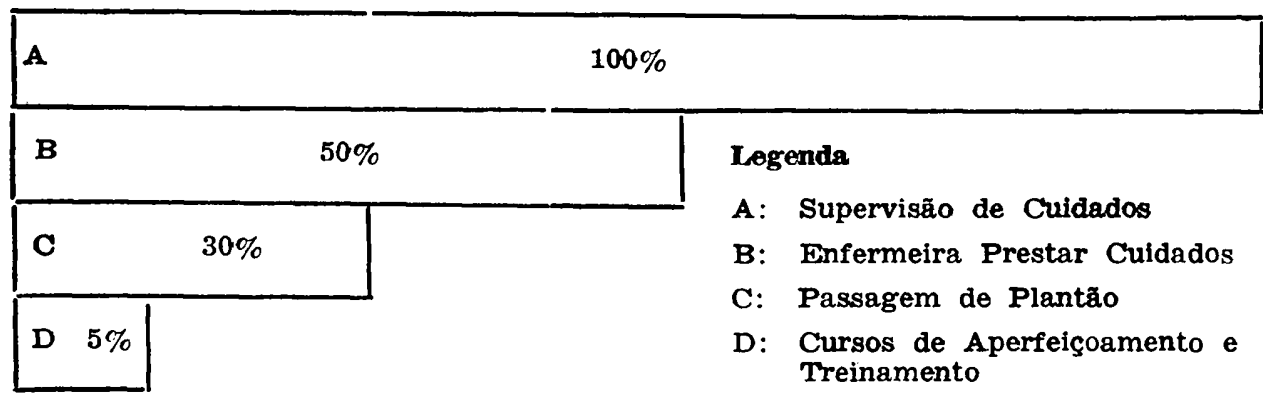




\subsection{Avaliação do curso de S.A.E.}

Quanto a avaliação do curso de S.A.E. no H.U., havia uma pergunta específica: "O que você achou sobre o Curso de S.A.E. no H.U.?" Obtivemos o segliinte resultido:

- $20 \%$ cias enfermeiras referiram como muito bom;

- $50 \%$ das cnfermeiras referiram como bom; e

- $30 \%$ das enfermeiras referiram como regular.

\section{CONSIDERA_ÇOES FINAIS}

Mediante a tabulação destes dados, análise das normas anteriormente estipuladas, bibliografias referentes ao Processo de Enfermagem e a experiência vivenciada durante 5 anos na aplicação desta metodologia, o grupo elaborou a reestruturação das normas da S.A.E.

A S.A.E. reestruturada foi implantada em 01-07-86 em todas as unidades atualmente em funcionamento no hospital (Pediatria, Clínica Médica, Pronto Atendimento, Centio Obstétrico, Berçário, Alojamento Conjunto, Clínica Cirúrgica e Centro Cirúrgico).

Estas normas reestruturadas serão apresentadas no XXXVIII Congresso Brasileiro de Enfermagem a realizar-se em outubro p.f. no Rio de Janeiro.

Continuamos portinto utilizarido ainda as três fases do Processo de Enfermagem: Histórico, Evolução e Prescrição de Enfermagem; mas com a preocupação de levar em conta a especificidede de cada unidade. Com a coordenação do grupo de estudo da S.A.E. cada diretora de unidade junto com o seu grupo de enferrneiras redigiu as rotinas especificas de sua área que passaram a não mais fazer parie da Prescrição.

Por ser o H.U. um hospital em que a Escola de Enfermagem da USP se faz representar através da diretoria, por uma de suas docentes, e de professoras que exercem a função de Supervisoras de Ensino e Pesquisa, existe uma preocuparão de que esta metodologia seja ao mesmo tempo exequível na prática mas com o suporte teórico neces, sário para uma atuação efetiva da enfermeira.

Neste sentido foi o:ganizado o I Curso de Aperfeiçoamento para todas as Enfermeiras Chefe e Docentes Supervisoras de Ensino e Pesquisa que atualmente estão em atividade no H.U. Aproveitaremos a oportunidade e colocaremos também uma enfermeira de cada unidade, para que elas possam enriquecer o grupo através da sua experiência diária e ajudar na orientação dos outros elementos da equipe, principalmente na situação de substituição de chefia. 